\title{
The capabilities approach and agency for shaping family formation trajectories in Ghana
}

\author{
Thomas Antwi Bosiakoh ${ }^{1,2}$, Samuel Agyei-Mensah ${ }^{3}$, John K. Anarfi ${ }^{4}$ \\ Adu Owusu Sarkodie ${ }^{5} \&$ Claudine Sauvain-Dugerdil $^{6}$ \\ ${ }^{1}$ Department of Sociology, Macquarie University, Sydney, Australia \\ ${ }^{2}$ Department of Sociology, University of Ghana, Legon, Ghana \\ ${ }^{3}$ Department of Geography and Resource Development, University of Ghana, Legon, Ghana \\ ${ }^{4}$ Regional Institute for Population Studies, University of Ghana, Legon, Ghana \\ ${ }^{5}$ Department of Economics, University of Ghana, Legon, Ghana \\ ${ }^{6}$ Institute of Demography and Socioeconomic, University of Geneva, Switzerland
}

Email: bosiakoh@gmail.com

\begin{abstract}
Context/Background: Developed by Amartya Sen, the Capabilities Approach (CA) has been applied in several domains of abstraction for understanding human well-being and development. However, there is very little about CA in the processes of forming families, particularly in Africa. This paper employs CA to examine the Ghanaian family formation trajectories. It explores the norms and preferences, the choices and decision-making processes, timing as well as constraints embedded in the family formation process.

Data sources and methods: This paper draws on a bigger Ghana/Mali qualitative research that contrasted individual realities and collective images of family formation trajectories in the two countries, but specifically focuses on the Ghana case to understand the individual family formation trajectories in terms of their family life histories, resources available to them as well as their notions on the ideal family life. It is based on analyses and discussions of thirty (30) in-depth interviews conducted in rural and urban Ghana.

Results:The results show an inherent interplay of agency-driven idealized goals and socio-cultural concerns, in other words, realities that reflect agency-structure concerns with regards to different family life domains (pre-marital relationships, partner choice-making, marriage, etc.).

Conclusion:Based on the analyses, we conclude that the concepts of 'ambivalence' and 'agency' are important in smoothening the difficulties family formation actors encounter in pursuing their personal family life goals within the context of socio-cultural family life requirements.
\end{abstract}

Keywords: Family formation; Pre-marital relationships; Capabilities approach; Ghana; West Africa

\section{Introduction}

Family formation and its trajectories in Africa have been of interest to researchers for some time now. Early consideration was primarily focused on the structure of African families and the context of high fertility in sub-Saharan Africa (Caldwell, 1965; Kilson, 1967; Caldwell and Caldwell, 1987; Oppong, 1974). The advent of HIV/AIDS also came with increased empirical treatment of the African family in relation to reproductive health (Awusabo-Asare et al. 2004; Adanu et al., 20l2), sexual networking (Anarfi and Awusabo-Asare, 1993; Anarfi and Appiah, 1997; Ankomah, 1999; Anarfi and Owusu, 201I), and contraceptive usage (Adanu et al., 2009). Beginning from the 1990s, there have been debates on fertility http://aps.journals.ac.za transition in the African family (see for example Frank and Bongaarts, 1991; Caldwell et. al., 1992; AgyeiMensah, 1996; 2006; Gould, \& Brown, 1996; Bongaarts, 2008; Shapiro and Gebreselassie, 2008) and the ways in which this transition is deemed to be different from what pertains elsewhere in the west (Bongaarts \& Casterline, 20I3). Other studies have examined how gender has been factored into explanations of fertility levels and fertility behaviour of sub-Saharan African populations (Dodoo and Tempenis, 2002; Dodoo and Frost, 2008; Frost and Dodoo, 2009). In recent years, research attempts have focused on religion and how it implicates reproductive and marital behaviours (see for example Heaton and Darkwah, 20I I). 
Thus, in a survey of the literature on the African family, there is less emphasis on the role of individual agency for shaping the formation trajectories. This is the focus of this paper. We contribute to understanding the norms that underpin the formation trajectories of the family in West Africa by drawing on the Ghanaian case. The paper focuses on the normative aspects and preferences, the choices and decision-making processes, timing as well as constraints embedded in family formation process in Ghana. The analyses are grounded in the Capabilities framework/approach with the view to equilibrate the attainment of personal family life goals within the context of socio-cultural family life domains. The Capabilities Approach, developed in the late 1970s early 1980s, encapsulates a broad normative framework for understanding human well-being and development, offering a new light on the agencystructure paradigm. Its utility is in its flexibility, thus making it applicable to different domains of abstractions.

This paper analyzes the Ghana case within West Africa where family demography has changed significantly. The aim is to better understand the roots of this trend, more precisely whether it is mainly resulting from institutional changes or changing individual norms and behaviours. The first part of the paper recalls the family demography as well as the policy and legal contexts. The second part presents the conceptual and methodological framework. In the third part, individual discourses are used to examine whether present changes express increased individual freedom of choice by referring to individual capabilities - in Sen's (1999) words 'The freedom to live the life one has to value'.

The Ghanaian context: population policies and family demography

Studies on family dynamics in Ghana actively started as early as the 1940s with Meyer Fortes' pioneering work on the Ashanti in 1948 (Oppong, 2005). Following this were proliferation of studies on different aspects of the Ghanaian family (e.g. Busia, 1950; Caldwell, 1965; Kilson, 1967) before the country had its first population policy in 1969. With this, Ghana became the first African country to adopt a comprehensive population policy (Kwankye and Cofie, 2015) and this affirmed the country's commitment to population issues (GoG, 1994). This population policy provided the frame for all population-related issues in Ghana untill it was revised in 1994 and accompanied by an Action plan. Although produced just before the Cairo Conference, it referred to the new paradigm of emphasis on the person and their wellbeing, especially women empowerment, and incorporated emerging issues of HIV/AIDS, environment, the aged and persons with disability, among others. Assessment of this policy in 2004 showed progress, but most targets set were not met, neither was its role as reference document for discussions on Ghana's population properly adhered to. Up to now, the Population Policy has not been revised, but has inspired development and sectorial policies. Noteworthy is the impressive improvement in access to reproductive health services through its inclusion in the National Health Insurance Scheme.

These policy documents and the family planning operations which accompanied them have ensured that people desire for small family sizes and promoted favourable attitudes toward 'modern' contraceptives. The overall aim has been to reduce fertility and eventually bring down population growth to be consistent with national development aspirations to improve the quality of life for the population. The trend shows that fertility levels have fallen to a reasonably low level in Ghana since the 1980s (Shapiro \& Tambashe, 1999). This has been attributed in part to the early population initiatives as well as economic improvement (Caldwell, Orubuloye, \& Caldwell, 1992). From 6.4 children in 1988 it has fallen to 4.2 in 2014 , the lowest in West Africa (Ghana Demographic and Health Survey, GDHS, 20I4). Contraceptive prevalence for modern methods among married women 15-49 increased from $5 \%$ in 1988 to $22 \%$ in 2014 ; unmet needs for contraception is estimated to be still $30 \%$. Rural women have two children more than their urban counterparts(5.I vs. 3.4) and use less modern family planning compared to those in urban areas $(19.8 \%$ vs. $24.8 \%)$ (GDHS, 20I4).

The 1994 Population Policy set nine-pronged objectives. Of relevance to this paper is objective 4 which seeks 'to educate the youth on population matters which directly affect them such as sexual relationship, fertility regulations, adolescent health, marriage and child bearing, in order to guide them towards responsible parenthood and small family sizes'(GoG, 1994:3). Additionally, the national youth policy identifies young people as vulnerable and therefore seeks to provide social protection in order to make their transition to adulthood less cumbersome (Ministry of Youths and Sports, 20 I0: |7-18).

Marriage is a central issue in family dynamics; it is considered an important life event in Ghana and nearly every Ghanaian practices or aspires to be in one (Awusabo-Asare et al., 2004). Given the importance attached to marriage, it sometimes forms the basis for assigning responsible roles to individuals. For example, reproductive, economic, and indeed some non-economic roles in traditional Ghana are http://aps.journals.ac.za 
assigned based on the marital status of the individual. As such, voluntary celibacy is a rare option in many parts of Africa including Ghana, and the norm has been to align with pro-natal and marriage ideology as the platforms for family formation and nurturing. Traditionally, and to some extent contemporary times, Ghanaian women marry early (Ankomah, 1999; Anarfi and Awusabo-Asare, 1993), and given family demands on men to provide bride wealth, this has tended to increase male authority in marriage (Frost and Dodoo2010). Therefore improving women's status with the hope that it would delay their entry into marriage is a central issue towards fostering a decline in fertility (Arkutu, 1995; McNamara, 1992; Kritz and Gurak, 1989). Even though the Children's Act of Ghana, Act 560 of 1998 restricts early marriages, setting the minimum age for marriage at 18 years, some customary practices like child betrothals lead to child marriages. Also, although the average age at marriage of women is now over twenty (20.7 in GDHS 2014), marriage before 18 is still frequent $(27 \%$ in the 201 I Multiple Indicator Cluster Survey) with the problem being more common in rural areas and among poorer women than in urban areas and among richer women (GSS, 20l I).

In the discussions that follow, we provide context for the Ghanaian family and inheritance systems.

\section{The legal context of Ghanaian family and inheritance systems}

In Ghana, the patrilineal and matrilineal kinship/family systems provide the framework for understanding native laws that administrate both the family and inheritance/property relations (Kpieta and Bonye 2012; Gedzi, 2009; Goody 1969). These kinship/family systems also form the basis or are expected to form the basis of family and inheritance laws in the country. Every Ghanaian is born into a kinship/family and this establishes the customary rights to property inheritance and to a larger extent, the socio-economic status of the individual. For example in patrilineal kinship/family system, the eldest son of a deceased person inherits the property of the deceased on behalf of his siblings (Kpieta and Bonye 20I2). Similarly, in a matrilineal kinship/family system property passes from one person to the other through a matrikin, that is, an eldest son of a maternal sister of a deceased person inherits the property of the deceased on behalf of his siblings.

In response to modernizing changes in the Ghanaians society, the government of the Provisional National Defense Council (PNDC) in 1985, promulgated the Intestate Succession Law, PNDCL III to administrate intestate succession in Ghana. The law sought to remove anomalies in intestate succession administration to provide a uniform intestate succession law applicable throughout the country irrespective of class, sex and ethnic persuasion of the intestate, and the type of marriage contracted by him or her (Republic of Ghana, 1985: i). At the time of its promulgation, the law appeared to be an important novelty in the Ghanaian family and inheritance landscape. It was flagged as a respite, not only for spouses, but also children left behind and helped draw the line on what proportion of the property ought to go to the extended family members. Prior to this law, the spouse and children often faced expulsion and other forms of hounding when the breadwinner of the family, usually the husband, died intestate (ibid). Thus, the law prevented members of the extended family from crowding out the surviving spouse and children on inheritance of assets of deceased persons for their own use.

After years, a number of inadequacies have been identified with this law. For example, the provision on fractional allotment of the assets of the deceased person has been difficult to operationalize. Additionally, no provisions were made for dependent parents, children of the deceased still schooling, and polygamous marriages still prevalent in several parts of traditional Ghana. Thus, these family constituents were compelled to share the same fraction of the assets allotted to them by the law. The law was also silent on how assets acquired jointly by the couple were to be shared on the death of one partner.

For now, the country is in a process of amending the 1985 Intestate Succession Law, PNDCL III. Amendment bill has already been formulated, and is expected to become the new law for administrating intestate succession in Ghana. The new bill contains provisions for dealing with the anomalies inherent in the present law and is thereby expected to bring about tranquility in intestate succession administration in Ghana. Thus, one has to recognize how in the process of making family formation (reproductive and fertility) decisions in Ghana, sociocultural and national laws/legislations provide important determining context. As things stand now, the intestate succession law seems to favour the nuclear family thereby undermining the stability of the bigger extended family.

\section{The theoretical frame - capabilities approach}

Our analysis focuses on the degree of individual agency expressed by interviewees in describing their family formation trajectory. In particular, we reference the notion of ambivalence, understood as the gap between norms and individual preference, i.e. described in the literature as a condition for changing behaviour. We draw this notion from the 
capabilities approach as a theoretical framework which enables consideration of the role of the person herself in the differentials in quality of life. Using the Capabilities framework to explore the family formation process is novel not only in Ghana and in Africa but also in population and family studies in general (Chiappero-Martrinetti and Venkatapuram, 20|4; Sauvain-Dugerdil, et. al, 20|4).

This approach, developed by the economist and Nobel Prize winner Amartya Sen in the late 1970s and early 1980s, encapsulates a broad normative framework for understanding human well-being and development. It is premised on the tenet that, development should be conceptualized in terms of the freedom people have to achieve valued outcomes. A key feature of the Capabilities approach is its flexibility which, as pointed out, enables it to endear to different domains of abstractions and in different socio-cultural contexts including those in Africa. Thus, the approach is applicable across different fields of study at different levels of abstraction (Chiappero-Martinetti et al, 20।2: 5).

The principal Capabilities framework questions applicable to this study are 'What enable people to chose the family life they value or have control over their family life? and What are the kind of families (beings and or doings) people enjoy? These questions are related and tied to Sen's (1999:3) conceptualisation of development 'as a process of expanding the real freedoms that people enjoy', which implies also, the set of capabilities that enable people to choose life they have reason to value. It is in this light that we explore the capabilities within which Ghanaian men and women (both urban and rural) choose and pursue family life they have reason to value (Fig. I).

Fig. I : Modelled capabilities approach for family life

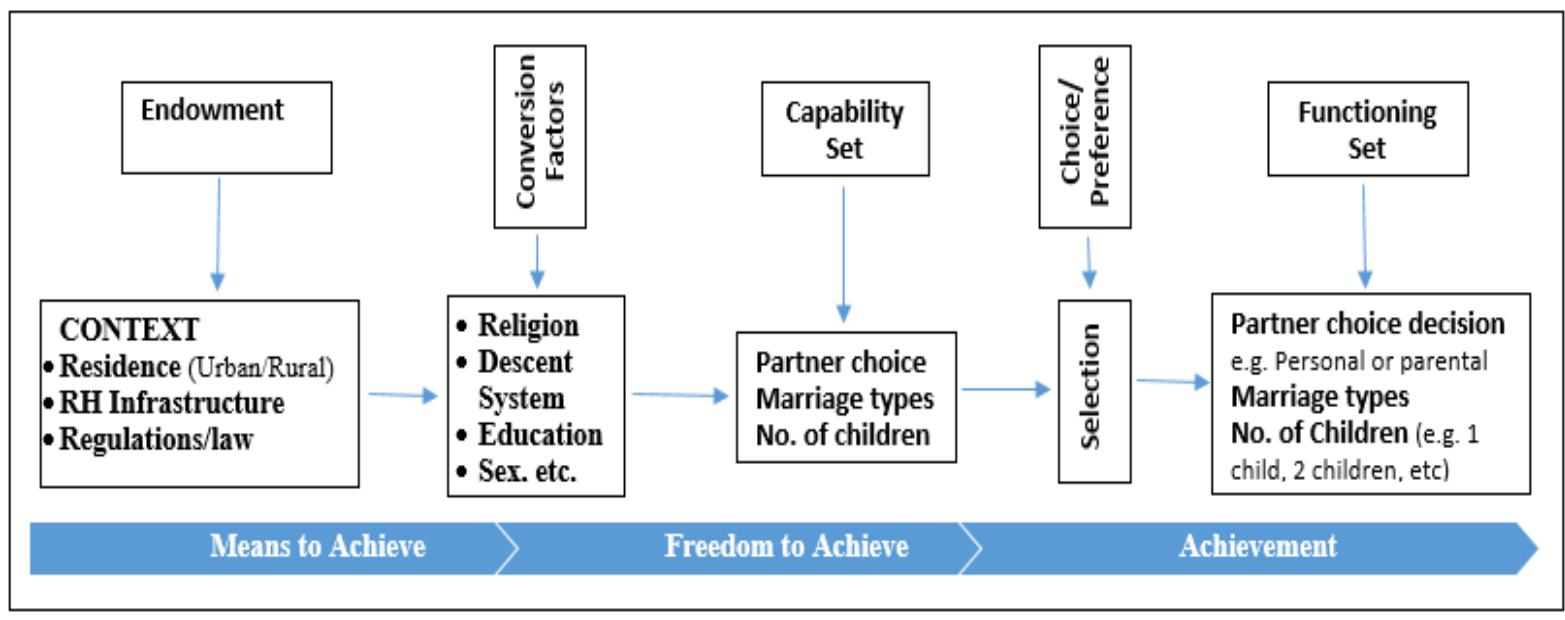

Source: Authors' construct adapted from Robeyns (2005).

The modeled Capabilities approach for family life reflects three key elements in the Capabilities approach. The first is the endowment context expressed in residence (rural and urban), the presence or absence of reproductive health infrastructure and the regulatory/legal context. The endowment is generally interpreted as the resources/platform with which to achieve. The second key element is the Capabilities set, the effective opportunities or real/substantive freedoms people have to choose regarding what to do (see Chiappero-Martinetti, et al., 20/2) or the options available to individuals regarding what to do. Here we identify three broad routes that shape their family trajectories: partner choice, marriage type and number of children. Individuals have the freedom to pursue/achieve options the Capabilities set presents. Functioning set (the actual achievements/outcomes, option realized by the individual or valued beings and doings one chooses to pursue and achieves) is the third key element and reflects the outcome among available options in the Capabilities set. Interspersed between endowment and Capabilities set are conversion factors, i.e. the individual, social and environmental characteristics that affect the ability to convert endowment resources into achievements. Here we identified religion, descent system, and education among others. This means that, individuals with same or similar endowments but different conversion abilities would end up with different real life family-formation outcomes. In order to translate options in the Capabilities set into achievements (functioning), individuals make choice regarding what their preferences are (see Fig. I).

A key dimension in the Capabilities approach is the notion of agency, implying a person's ability to pursue goal(s) that they have reason to value. From the Capabilities point of view, individuals have to be seen as being actively involved in shaping their own 
destinies and not just as passive recipients (Sen, 1999). An agent is therefore 'someone who acts and brings about change, and whose achievements can be judged in terms of her own values and objectives' (Sen, 1999:19). But to be able to do this, agents/actors must be provided with the opportunity to do so. In other words, the platform to be employed to be actively involved in shaping the destinies must be provided.

A way to consider agency is through the concept of ambivalence which has seen application in the field of intergenerational relationships (see for example Lüscher, 201I; 2004; Lüscher \& Pillemer, 1998; Pillemer \& Lüscher, 2004) and applied by SauvainDugerdil (2005) to family demography. In its simplest form, ambivalence denotes the presence of dualistic notions, ideas, attitudes, or emotions at the same time. This dualism could be expressed in terms of how a person formulates his/her own personal project (one of the Capabilities set items) but the achievement of this project conflicts somehow with the socio-cultural context within which to execute and achieve this project. Thus, the concept of ambivalence provides a framework for measuring the importance of personal preferences against realities and ideal of normality (Lüscher, 20II: 195) and draws attention to the socio-cultural fortresses that confront actors in the pursuance of personal goals and objectives, and the conflict that this engenders. Thus, ambivalence as a concept is "useful for overcoming the dichotomy between the subject and its (social and physical) environment' (ibid: 196) as individuals pursue the life (personal project) they have reason to value. Therefore, in Figure 2, we introduce i) agency as a mediating predictor of family formation achievement - the individual's ability to pursue goal(s) he/she has reason to value, including the preferences/choices to be made, and ii) ambivalence - how the choices come face-to-face with socio-cultural normality. This process constitutes the 'workshop' producing the actual achievement/outcome/option realized by the individual.

Fig. 2: Conceptualization of capabilities - functioning relationships with agency and ambivalence

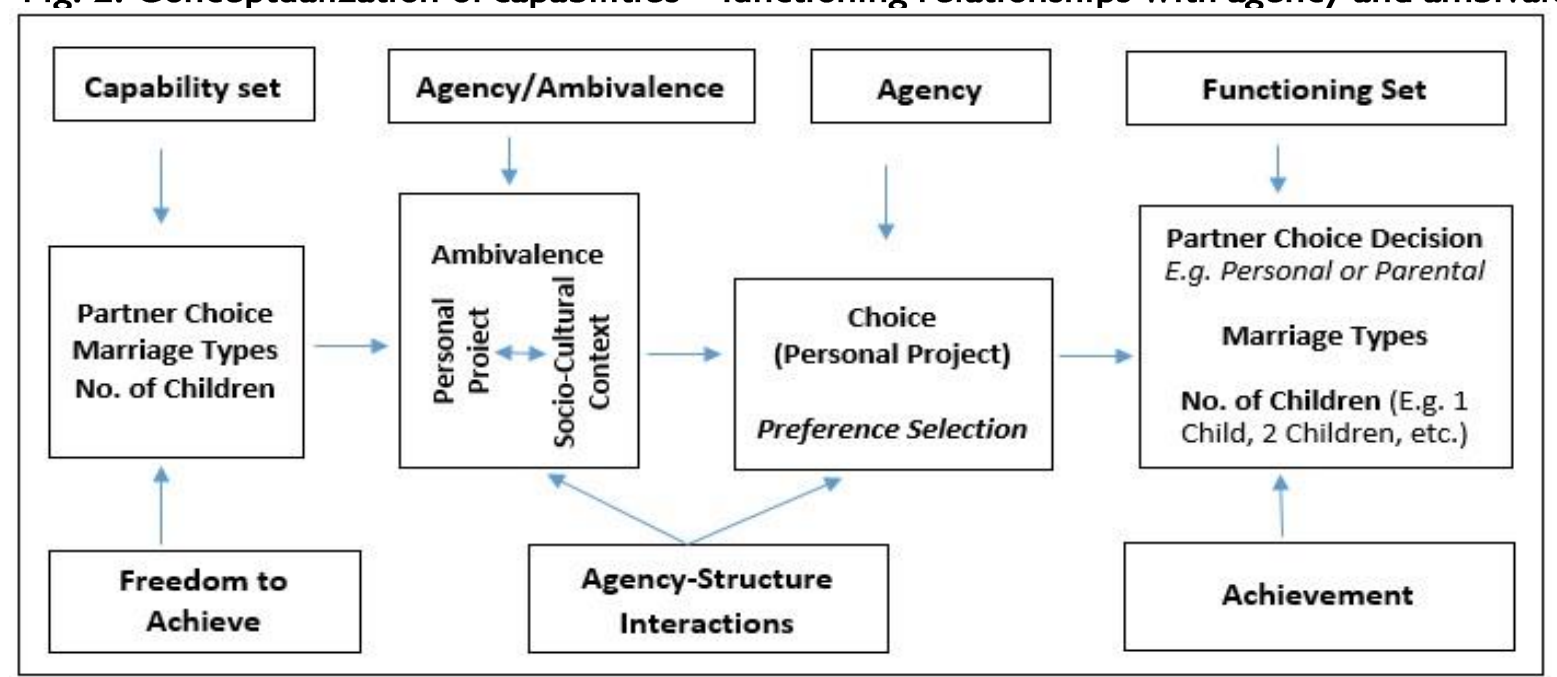

Source: Authors' Construct

\section{Data, methods and characteristics of respondents Data and methods}

This paper draws on analyses and discussions of thirty (30) in-depth interviews conducted as part of a broad qualitative survey (Focus group discussions, interviews and observations) that contrasted individual realities with collective images in Ghana and Mali (Sauvain-Dugerdil, et. al., 20l4). In this present paper, we offer more depth of the Ghana case to understand the individual family formation trajectories in terms of their family life histories, resources available to them as well as their notions on the ideal family life.
The interviewees were initially selected to distinguish groups of people that share similar characteristics, what had been called, to follow the Capabilities terminology, as 'endowment groups'. Ten such groups were identified comprised between 5-7 members for the FGDs. Five (5) FGDs were in rural areas (represented by Ntonkrom and Kintampo) and the other five (5) in urban areas of Ghana (University of Ghana, Nima, Mempeasem and Staff Village). Two (2) of the groups were created with emphasis on patrilineal and matrilineal kinship inheritance systems and four groups with emphasis on the presence or absence of reproductive health programmes. Six (6) of the groups were comprised of women and four (4) by men (see Table I). 
The characteristics of each endowment group was homogenized but taken together with other groups, represented diverse polarities that reflected both traditional and modern dynamics of family behaviours in Ghana. As this study is a qualitative one, the selection of initial respondents (FGDs) was purposive through word-of-mouth, as in conversation with people in the study areas, but guided by the criteria enshrined in the endowment groups. This was expanded through chain referral approach. For interviewees who did not participate in FGDs, the selection was through chain referral from their FGD counterparts. Both FGDs and interviews were conducted at places agreed to by the participants.
Ethical principles including privacy, voluntary participation and informed consent were strictly adhered to. Participation in both FGD and interview was voluntary and full consent obtained. Participants were also free to terminate their participation at any time. The data were also kept confidential and used only for our research purpose. All the transcripts were anonymized, so were the names used in this paper. The discourses have been analysed/managed with the Atlas.ti software package.

Table I: Selection of respondents (endowment groups)

\begin{tabular}{lll}
\hline & Criteria definitions for selecting endowment groups & Selection place \\
\hline Group I & Women, rural, no schooling, with economic activity \& high density RHPs', patrilineal & Kintampo \\
Group 2 & Women, rural, no schooling, with economic activity \& high density RHPs', matrilineal & Kintampo \\
Group 3 & Women, rural, no schooling, with economic activity \& low density RHPs', patrilineal & Ntonkrom \\
Group 4 & Women, rural, no schooling, with economic activity \& low density RHPs', matrilineal & Ntonkrom \\
Group 5 & Women, urban, high education (secondary plus), with professional activity & UG $^{2}$ \\
Group 6 & Women, urban, high education, without professional activity & Nima \\
Group 7 & Men, rural, non-agricultural activities, religious & Ntonkrom \\
Group 8 & Men, urban, middle-high education (secondary plus), charismatic & UGSV $^{3}$ \\
Group 9 & Men, urban, middle-high education, evangelistic & UGSV $^{3}$ \\
Group 10 & Men, urban, middle-high education, catholic & Mempeasem
\end{tabular}

$\mathrm{RHP}=$ Reproductive health programme; UG = University of Ghana; ${ }^{3}$ UGSV = University of Ghana Staff Village

\section{Characteristics of interviewees}

The material of the present study is based on thirty in-depth individual interviews. Twenty (20) were selected from participants in the FGDs (2 each from the 10 FGDs), another ten persons, who did not participate in the focus group discussions but possessed characteristics similar to those of the FGD participants, were identified and interviewed. The characteristics of the interviewees (Table 2), structured by the endowment criteria, shows that females outnumber males, the proportion being $58 \%$ females to $42 \%$ males. While most interviewees were in the 20-49 age regime, this was dominated by the 20-29 cohort. More than half of the interviewees were in this age category. Male interviewees were more educated than females: of the 19 interviewees with formal education, I 3 were males; also, of the I 3 interviewees with bachelor's degree, 9 were males. There were more Christians than Muslims. Though the rural/urban distribution was even, females were more in rural areas and males more in urban areas. Similarly, there was even distribution of marital statuses (married/not married) but more females were married compared to males. Majority of the study respondents $(61 \% ; n=19)$ had at least one $(1)$ child with females more likely than males to have a child. About a third of the interviewees $(29 \% ; n=9)$ were students and the rest engaged in economic activities, mainly farming, trading and teaching. 


\begin{tabular}{|c|c|c|c|c|}
\hline & & & & Total \\
\hline \multirow{6}{*}{ Age } & & Male (13) & Female (18) & \\
\hline & $20-29$ & 7 & 9 & 16 \\
\hline & $30-39$ & 2 & I & 3 \\
\hline & $40-49$ & i & 6 & 7 \\
\hline & $50-59$ & 2 & - & 2 \\
\hline & $60+$ & 1 & 2 & 3 \\
\hline \multirow[t]{5}{*}{ Education } & No formal education & - & 12 & 12 \\
\hline & SSSCE & - & I & 1 \\
\hline & Post-secondary & - & 1 & I \\
\hline & Bachelor's degree & 9 & 4 & 13 \\
\hline & Others & 4 & - & 4 \\
\hline \multirow[t]{2}{*}{ Religion } & Christian & I I & 13 & 24 \\
\hline & Moslem & 2 & 5 & 7 \\
\hline \multirow[t]{2}{*}{ Location } & Rural & 4 & 12 & 16 \\
\hline & Urban & 9 & 6 & 15 \\
\hline \multirow[t]{2}{*}{ Marital status } & Married & 5 & 11 & 16 \\
\hline & Not married & 8 & 7 & 15 \\
\hline \multirow[t]{5}{*}{ No. of children } & No child & 9 & 3 & 12 \\
\hline & $1-2$ & I & 6 & 7 \\
\hline & $3-4$ & I & 5 & 6 \\
\hline & $5-6$ & 2 & 3 & 5 \\
\hline & More than 6 & - & I & 1 \\
\hline \multirow[t]{6}{*}{ Economic activities } & Trading & - & 4 & 4 \\
\hline & Farming $+^{*}$ & 4 & 6 & 10 \\
\hline & Teaching & - & 3 & 3 \\
\hline & Hair dressing & - & 2 & 2 \\
\hline & Student & 9 & - & 9 \\
\hline & Others & - & 3 & 3 \\
\hline
\end{tabular}

+ *: Plus something else, e.g. teaching, gari processing, masonry, etc.

\section{Family formation trajectories}

The empirical results are discussed to bring out the key issues at play in trying to understand the norms for shaping family formation trajectories in Ghana. First, we discuss the family formation trajectories with emphasis on courtship and pre-marital relationships, choice making regarding marriage partner and the marriage itself. Secondly, we discuss developments after marriage and what in the estimation of the interviewees, led to the problems they encountered in their marriages.

\section{Courtship and pre-marital relationships}

Generally, dating and pre-marital relationships were frequent occurrences among the interviewees, both urban and rural. While some interviewees, both rural and urban e.g. Edem, Ellie, Kofi, Mehdi engaged in it at the time they were undergoing training as apprentices and/or students, others like Sylvia and Yaw, also both rural and urban entered into courtship after they had completed their training/schooling. http://aps.journals.ac.za
Engaging in pre-marital relationships was not circumscribed on any particular endowment group. It straddled across all the endowment groups including the devoutly Catholic men, even though the practice had been halted by many, and no attempts had been made to re-engage in pre-marital sexual activity. Some interviewees engaged in pre-marital relationships much early in their lives at the Junior High School(JHS) level (e.g. Kofi and James, both urban) and for some others, this occurred after school (Jock, rural) or when they had found jobs and were working (Sylvia, urban). In addition, we found evidence of pre-marital relationships occurring in the contexts of offering and receiving help (Ben, rural and Nick, urban). These episodes on pre-marital relationships among the interviewees (both rural and urban) suggest that, sexual experimentation/sexual socialization was a part of their family formation trajectories. Some narrative extracts illustrate how, for some interviewees, pre-marital sexual 
engagements were part of their family formation trajectories.

One interviewee (Kofi, a final year university student) indicated that, he '... started dating when I was in SHS 3', and another indicating as follows: 'Yes, I used to hang around with my friends when I finished my SHS and that was how I met her' (Mehdi, also a final year university student). In $\mathrm{SH} 2$ without any prior thinking about it, one interviewee indicated that he started friendship and ended up in serious dating. Recounting the circumstances that led to his engagement in pre-marital sexual relationships, this interviewee observed as follows:

'It started in SHSI. I forgot my place in the dining hall so I was sacked and when I got to the dormitory the girl sent a message to me. Upon going to meet her, I realized she reserved some of her food for me and she said she did that because she saw me being sacked from the dining hall. I also gave a gift in return and that continued till we started dating ... (Nick, urban).

Two contrasting notions emerged from the interviews in relation to the value of pre-marital relationships. One view suggested that they help the individual actors to deal with troubles in life and that without a pre-marital partner, the individual will find it difficult to deal with the problem. In the following quote from one of the interviewees (Nick, Urban, 28yrs, \& not married), we find how, premarital relationship is conceptualized in terms of dealing with troubles, unmindful of moral questions that others may raise.

'As an adolescent when you are in a relationship and you have a problem, you would just go to the person and by the time you come back you are ok but if you don't have one, that's when you roam about' (Nick, urban).

Additionally, pre-marital relationships were abstracted as a platform for nurturing plans of marriage. This observation was supported by a number of statements linking pre-marital relationships to marriage. While for some interviewees (mainly rural), it was through premarital relationship that they got married (Emma, Awo, Yaw, Kais, Jock), for some other interviewees (mainly urban), they hoped their relationships would soon lead to marriage (eg. Isaac, Bee). Confirming the link between pre-marital relationships and marriage, one interviewee observed as follows: 'Yes, we started when we were young and later got married so he is the only one that I've been with' (Emma, rural). Another interviewee had a slightly different account 'She got pregnant whiles we were courting so we had to come together' (Jock, rural).

Contrasting the positive notions on pre-marital relationships were other views spinning out the negativities on pre-marital relationships such as how they come about as well as their outcomes. If they were good, pre-marital relationships would not be the result of peer pressure (James, urban) and often times, lead to teenage pregnancies when the actors are physiologically, psychologically and economically unprepared. When pre-marital relationships lead to teenage pregnancy, they have the tendency to push both the teenage mother and her child to the street. 'Some of the street children that we have today are results of people not being ready before entering into relationships. Left to me, I would advise that everybody should wait until they are ready before entering into a relationship' (Andrew, urban).

\section{Marriage partner choice-making}

How do people make choices regarding their spouses/partners? What are the key considerations that underpin the choice of a marriage partner? This question of choice is treated as important because of its ties with the Capabilities approach (see Fig 2). Two key themes emerge from this study about who makes the decision on one's marriage partner. The first has to do with the family, and the second by the individuals themselves. Regarding the first, only one interviewee, a rural woman with patrilineal descent (Awo), indicated that the choice of her partner was made by the family. In her case, it was the father who made the decision for her and as she puts it, 'That was how it was in those days; it is your father that would choose a husband for you' (Awo).

For many of the interviewees, the choice of marriage partner is a personal decision. One case to illustrate this point of view is provided by interviewee Afia, a 40 year old rural mother of 4 children with matrilineal descent. Afia was persuaded by her mother to marry her own uncle (family/socio-cultural context influence). 'My mother wanted me to marry my uncle because of the difficulties we were going through'. It took personal will (agency) from Afia to neutralize this idea. Thus the idea that parents make choices regarding marriage partners is fast loosing grounds to personal decisions. This however is not to suggest that, families and the general socio-cultural contexts remain passive and apathetic about individual choices regarding marriage partners.

What parents resort to which is reflected in much of the interviews, is to offer advice as in '...they can only give advice' (Peter, urban). Thus, the most domineering theme on the subject of who makes the decision on one's marriage partner was the one made by the individuals themselves - their independent decisions. Most marriage proposal accounts reflected the view that, the man makes/made the proposal as in 'He saw me and said he wanted to marry me' (Afia, rural), or 'I talked to her and she understood me' 
(Yaw, rural) and the woman accepts/accepted it. And though the men made the proposals, the women spoke proudly about their roles in the choice-making (that they made the choices themselves) (Emma: 'I chose him by myself'; Ruth: 'I chose my husband personally'; Nancy: 'I chose him myself'). The emphasis on choosing one's partner personally suggests that, parental influences (not advice) were less countenanced in the considerations to choose one's marital partner. One of the most direct statements on how marriage partner choice-making should be selected was provided by Franklin, urban: 'It should be of free will so I believe it would be a personal choice'. However, parental/family approval of one's proposed partner is always sought before the proposed marriage could be solemnized. In this way, respondents' accounts on partner choices and the decision context (personal and family) reflected a balance of both idealized personal preferences, as well as a concern for family/group acceptance (sociocultural context), that is to say a situation of ambivalence.

And what are the qualities expected in a marriage partner? Our analyses reflected issues bothering on compatibility, true love, understanding, care, personality and educational level. Compatibility was advanced by Franklin and Kofi, both urban but was better articulated by Franklin as follows: '... marriage is all about spirituality so I would ensure that our spirits are the same'. While for some interviewees, the quality expected from a partner should be true love '... it shouldn't be based on anything but true love which would stand by you in anything' (Peter, urban), for others, it should be care (e.g. Kofi) and personality (Mehdi, Andrew). The educational level of the prospective partner was also mentioned as a key attribute: 'the ultimate is that the person must either be in a tertiary institution or should have completed' (Andrew). Gleaning from the data, interviewees tended to select their relationship partners based on a number of romantic options; casual (less mentioned), short-term sexual relationships (less mentioned); and dating toward a long-term relationship (often mentioned). In many accounts, marriage emerged as a venerated option/end in premarital relationships.

\section{Marriage life}

The discussions on marriage are framed on three themes - timing, number of children and intervals between births, and in cases where there was a perceived notion of a co-partner, the prevailing relationship between them. As we noted earlier, some interviewees engaged in pre-marital relationships at the time they were schooling/undergoing apprenticeship training. There was largely a shared understanding that, pre-marital relationships often led to marriages. Given the fact that some interviewees engaged in such relationships early in their lives (at the time they were schooling or undergoing apprenticeship training), this translated into marriages for some of them (e.g. Afia, Ruth, Yaw, Jock). In some cases (particularly in rural areas), the pre-marital relationships led to pregnancy (e.g. Yaw, Jock) thereby leading to forced marriage.

For some other interviewees (both rural and urban), marriage was not as a result of pregnancy that emanated from pre-marital relationships (Betty, Sylvia, Ben). Lack of support to learn a vocation after school was cited by one interviewee implying that, marriage occurred after completing school even though it also had some element of force 'When I completed form four (4), I did not get anybody to support me to learn a trade so I got married' (Betty, rural). It is clear from this account that, the interviewee did not intend to marry at that time. Perhaps there was willingness to pursue further education but because there was no support, she ended up in a matrimonial relationship.

However, the case of Ben, rural, depicts strong prior intention to marry before the actual marriage occurred. This is unlike the cases discussed which had forced elements in the marriage decision. Ben went straight to ask for marriage when he realized he needed to marry, and when the woman accepted his proposal, he married her. He observed as follows: 'I went to see her personally to marry her so that she can help me on the farm. She understood and so I went to see her parents and did the necessary things that needed to be done. After, I brought her to my house and she helps me with my food and other things'. Thus, the decision to marry can also be grounded in the Capabilities frame. While some respondents yielded to the demands and dictates of the socio-cultural norms, others formulated their own convictions. Those who yielded to the sociocultural dictates included respondents whose premarital relationships led to pregnancy and marriage as well as those who lacked support to learn vocation after school. For these respondents, there was no element of prior intention to marry.

Our data does not show any respondent engaged in polygamous relationship/marriage. However, four respondents ( 3 rural and I urban) were quick to indicate that their partners had been playing with other girls (Afia) or they suspect that (Emma, Bee, Anita). Complain about this had led to serious brawl (Afia). Emma indicated what she would do if her suspicions of unfaithfulness on the part of her partner is proved right: 'I will leave quietly'. Other respondents (Ellie, Thess) would 'first ask the man to make a choice' between them. 
The number of children the respondents had ranged from $0-10$. The highest number of children recorded was 10 (ten) by a 70-year old energetic rural woman (Awo). Two (2) interviewees had six (6) children (Kais, Jock), two (2) others had five (5) children (Edem, Anita). There were a number of the interviewees with either two (Ruth, Efe, Betty, Yaw) or three (Sylvia, Ama, Ben, Eva) children, but majority of them had no children.

A key measure for controlling birth, as found by Hagan and Buxton (20I2) is contraception. In this study, contraception was identified for birth control, i.e. for spacing and limiting birth, even though it was not a topic spontaneously mentioned. When asked, many of the urban men and women answered that they use condom and specific pills, while rural respondents used contraceptives without knowing the specificities except to say that they were for birth spacing. Though there was high knowledge and awareness of contraception among the interviewees, it appears usage was low to limit births, thus showing in the number of children/births. While many of the interviewees agreed that, having too many children was unnecessary, the data shows that, rural men and women had higher propensity to have more children compared to their urban counterparts. Some rural men and women grumbled about their inability to give birth to a third child, and more children (e.g. Betty, Yaw). Though both rural and urban interviewees understood the economic implications of giving birth to many children, urban interviewees were more likely to shape their fertility behaviours according to economic exigencies. Rural women typically attributed the care of a child to God. One interviewee for example intimated that, 'Nyame na shwemmofra' (Edem), translated as 'It is God who takes care of children'. Conversely, urban interviewees narrated what it takes to send a child to school and it appears it is based on these that they limit the number of children they have through contraception.

\section{Developments of family life after marriage}

This section discusses developments (problems) that occurred after interviewees got married. The discussions are framed on the cause(s) of family life problems after marriage, and the ways in which these family life problems were dealt with. There were no attempts to know the kinds of problems interviewees encountered after their marriages but in the process, some of these problems filtered into the discussions. The preoccupation was to understand what the interviewees themselves thought they did not have (resources, capacities, skills etc.) and thereby brought about problems in their marriages. A number of issues were mentioned by the interviewees as the cause(s) of problems after marriage. These issues are categorized into three for better appreciation. They are illiteracy, lack of family support, and early child birth/refusal to heed to advice. These issues were mentioned in different ways as the cause of family life problems in the matrimonial homes of interviewees.

\section{a) Illiteracy}

Illiteracy in this discussion has broad application. It refers not only to lack of education/schooling but also lack of certain skills, competences and capacities, as well as ignorance and lack of some relevant information. Interviewees pointed to what we can refer to as different 'lacks' and it is these 'lacks' that in their estimations, caused the problems they encountered in their family lives. Key among these was lack of education and schooling. This was particularly mentioned by rural women with both patrilineal (Awo) and matrilineal descent (Nancy, Betty) systems. The following are quotations of how some interviewees connected their family life problems to lack of education and schooling: one interviewee indicated that, the 'family life would have been better if I had gone to school but unfortunately I didn't go to school' (Awo). Another interviewee added, 'My life is like this because I did not go to school' (Nancy).

And while some interviewees connected their family life problems to lack of education and schooling, others linked them to lack of some specific capacities and capabilities. They did not have education and schooling just like Awo, Nancy, Betty, etc., but for these interviewees, it was not the lack of education and schooling that brought about problems in their family lives. Rather, they mentioned lack of some specific skills and capabilities: 'Yes, I did not go to school, but if I were sewing, dressing hair or trading, it would have been of great help' (Ruth). For this interviewee and indeed a few others, individuals could lack education and schooling but could live meaningfully if they had employable competences, e.g. learning some relevant skills and capabilities in life. These skills are basically in the realm of vocation (sewing, hair dressing or trading, among others), thus suggesting alternative route(s) away from formal education/schooling with which individuals could have meaningful family and personal lives.

Some observations connected the argument on illiteracy to lack of some relevant information or ignorance (Nancy, Efe, Thess). This was aptly expressed in these episodes - one in a manner that led to separation, and the other leading to regret:

'I didn't get information anywhere early enough like just accepting someone that I think loves me without considering myself. I later learnt that it is a give and take affair and it is two people and not http://aps.journals.ac.za 
one. When I realized that he was committed and I wasn't, I just told him that it was ok and so we separated' (Thess).

'I got to know only when I became old that life would have been better if I had gone to school. This, I regret (Nancy).

\section{b) Family support}

Besides illiteracy, lack of family support was identified as contributing to the problems interviewees encountered in their families/relationships. In patrilineal (e.g. Awo) but largely matrilineal settings (e.g. Ruth, Nancy, Kais, Ben), interviewees mentioned their fathers as the family member they did not get support from. Few interviewees in matrilineal settings (Edem, Yaw) also pointed to both of their parents in general and one interviewee in a patrilineal setting (Emma) mentioned the grandparents as the persons they did not get support from. The narrative indicates how interviewees' families neglected them in their growing days. Thus, there is a link between illiteracy and lack of family support: lack of family support contributed to illiteracy as their parents refused to send them to school. This way, the two factors (illiteracy and lack of family support) contributed both independently and in association with each other, to the problems in the interviewees' families. Our expectation regarding the key persons to be mentioned in matrilineal settings as responsible for sending the interviewees to school was the uncle. The data however does not resonate with this expectation. This suggests not just a possible retreat of uncles in the upkeep and welfare of nephews and nieces but more generally the breakdown of normative expectations in descent systems.

\section{c) Refusal to heed to advice}

For some respondents both rural and urban (e.g. Nancy, Efe, Ama, Nick), the cause(s) of problems they encountered after marriage emanated from their own refusal to heed to advice, from parents, other family members and friends. Nancy and Efe indicated that life became difficult and problematic because they became obstinate: 'I was advised but I did not pay attention to them; that's why I am here today' (Efe). For this interviewee, just like many other interviewees, the problem was not because she did not have anybody to care for her education. As she puts it, they wanted me 'to continue my education but because I was stubborn, I got pregnant and couldn't continue' (Efe). Similarly, Ama noted she was responsible for her problems because she did not study hard enough in school. Broadly speaking therefore, these interviewees (Nancy, Efe, Ama,
Nick) thought they found themselves in their problems because they refused to heed to advice from parents, family members and friends. Consequently, as one of them poignantly observed, part of the explanation for the problems she encountered was 'because of how the children came in so quickly'. She noted that, 'my first child was one (I) year and three months old when I gave birth to my second child so I had to carry both when I was going to sell and it wasn't easy' (Nancy). As shown by several studies (see for e.g. Kumar, et al., 20I2), early motherhood is a predictor, not only for less utilization of maternal health care services, but also increased risk of maternal and child health outcomes. Thus, these interviewees stand the risk of not utilizing maternal healthcare services with serious implications also for child health outcomes.

\section{Discussion}

We have examined individual experiences of family formation in Ghana through key nodes including courtship and pre-marital relationships, partner choice-making, marriage itself, developments after marriage, as well as what respondents thought were responsible for the problems they encountered in their marriages. First, we show how courtship and pre-marital relationships form important pathway for entering family life. The analyses reflected the influential values, or perhaps utility values (Kaufman \& Stavrou, 2004), that are associated with these relationships, for example as an idealized pathway for marriage (entry served to provide sexual experimentation/sexual socialization), as well as response to exigencies of life (mainly economic). These are irrespective of religion and ethnicity. Langille (2007) demonstrates that there are three factors that influence young people to practice sex (individual, family and other factors). Our findings lend credence to the 'other factors', in particular to socio-economy (Manaf, et. al, 20l4; Wong, et. al., 2009; Langille, 2007). Additionally, acts of kindness and gift-giving set the parameters for courtship and pre-marital relationships (Kaufman, \& Stavrou, 2004). Our findings further show that young people appear to enjoy a high degree of freedom in premarital relationship. However it is clearly recognized that this period of freedom is a platform to prepare marriage. Ambivalence is therefore low because behavior is not in conflict with norms; on the one side, social control interferes little with premarital relationships and, on the other side, young people appear not to question that it will end up with marriage.

In turn, partner choice-making regime of the interviewees demonstrated ambivalence - a search for balance between personal preferences and concern of the family. The personal choices of 
individuals which manifested agency and instrumentality were to be guided by advice of parents in what can be described as an ambivalence process. Here we see parental involvement in terms of advice they provide. This is similar to the partner selection processes of Turkish and Moroccans in the Netherlands (Van Zantvliet, et. al., 20I4), and thus contributes to research on third-party influence on partner choice. In our case, especially when cast in the ambivalence construct, it is the resolution of agency-structure 'struggle' that gives way to functioning set/achieved functioning, i.e. the eventual partner. This means that, the decisions and choices reflected inherent negotiations or perhaps struggle between personal idealized projects and the sociocultural determinants/context and realities. This situation is better accounted for in Figure 2 than in Figure I because of the introduction of ambivalence which recognizes choice in agency and socio-cultural structure in the making of functioning sets/achievement. This thus helps capture partner choice-making process especially with the involvement and influences of parents which is more reflective of the Ghanaian cultural and or family settings.

A key dimension of the Capabilities Approach particularly when considering agency through the lens of ambivalence - is the access to resources. Individual agency and the ability to solve ambivalence are framed by the resources that they enjoy or not. In the present study, interviewees recognize the role of the lack of resources in the problems they encountered in their family trajectory, putting emphasis on illiteracy, lack of skills, lack of family support and of advices. Pre-marital stage of life is characterized by high degree of individual autonomy; the family interferes little and personal resources appear to be a factor particularly important, especially to avoid premarital pregnancy. Unequal resources appear also central in the acquisition of decision power for mate selection and it is well highlighted by the gender differences.

From both empirical and theoretical points of view, this paper sheds light on the Ghanaian family in a way different from classical treatment of the African families. By analyzing the formation trajectories, preferences, the choices and decision-making processes, timing as well as constraints embedded in the formation process, our analysis incorporates agency into the discussion of family formation. Agency appears however to be embedded into sociocultural structures. Individuals' achieved family goals are therefore to be understood as embodying sociocultural mediation elements (Ahearn, 200I; Ortner, 2006; 200I) and their own initial family project in an ambivalence process or 'workshop' with functioning set outcome(s). Agency appears anchored into the person's means. This allows discussing our results in the light of our initial research question, i.e. what makes the Ghana case special in West Africa. People have acquired more individual autonomy and are starting to question traditional norms. It was clearly shown in our previous paper (Sauvain-Dugerdil et. al, 2014) that it is much more the case than in Mali. As highlighted by the Capabilities perspective, individual ability to 'choose the life they have reason to value', is tightly dependent upon the resources they can access. In other words, the political, legal and institutional environments play central roles in opening new opportunities. In this regard, progress in years of schooling on average 7.6 in 1980 and II .2 in 20I4; 2.1 and 7.5 in Mali (UNDP, 20I8) and in health (infant mortality of 93 to 55 per 1000 births in Ghana, and $|5|$ to 100 in Mali (United Nations, 20|3) are central contributory factors. Similarly, a legal framework favorable to nuclear family plays certainly a role in value changes. But reproductive health policies and programme do not appear to have a big impact. Pregnancies out of wedlock are seen as the result of lack of resources and contraception has not been spontaneously mentioned, moreover it still appears to be less understood, especially in the rural sector. From this line of thought, policy and programme interventions for addressing problems in partner and family decision-making at the onset of marriage/family formation at both community and national levels need to envision the ambivalence process involving not only the offer side - structure but also individual resources and agency.

Moving further in our understanding of the Ghanaian family trajectories, studies should take into account their embeddedness into local cultural norms and how these norms structure the trajectories of the family. Already, Nukunya (2003) has noted that the Ghanaian family is undergoing increasing nucleation but the ways in which this process is reflective of nuanced contextual realities including ethnic and marital norms, economic exigencies, and individual preferences, among others is less understood. Thus, questions regarding the norms and preferences for future family formation processes and associated configurations in Ghana, and Africa in general, should engage such studies. As several aspects of the Ghanaian and West African societies undergo social change, not least in the area of family demography, it would be important to understand these developments in the light of family-related social changes and their interplay with economic constraints. 


\section{References}

Adanu,R. M., J. Seffah, J. K. Anarfi, N. Lince, and K. Blanchard (20|2). Sexual and Reproductive Health in Accra, Ghana. Ghana Medical Journal, 46(2): 5865.

Adanu, R. M. K., J. D Seffah, A. G Hill, R. Darko, R. B Duda and J. K Anarfi (2009). Contraceptive Use by Women in Accra, Ghana:Results from the 2003 Accra Women's Health Survey.African Journal of Reproductive Health, I 3(I): I 23-I 34.

Agyei-Mensah, S. (2006). Fertility Transition in Ghana: Looking Back and Looking Forward. Population, Space and Place. I2(6): 46I-477.

Agyei-Mensah S. (1996). New Perspective on the Fertility Situation in sub-Saharan Africa. NorwegianJournal of Geography 50(2): I0 I-I I 2.

Anarfi, J. K. and A. Y. Owusu (20I I). The Making of a Sexual Being in Ghana: The State, Religion and the Influence of Society as Agents of Sexual Socialization. Sexuality and Culture, I5(I): $\mid-18$.

Anarfi, J. K. and B. N. Appiah (1997). Sexual Behavioural factors predisposing 'Street-involved' Youth in Accra to HIV/AIDS Infection. African Population Studies, I 2(I).

Anarfi John K. and Kofi Awusabo-Asare (1993). Experimental research on sexual networking in some selected areas of Ghana. Health Transition Review, 3:29-43.

Ankomah, Augustine (1999). Sex, Love, Money and AIDS: The Dynamics of Premarital Sexual Relationships in Ghana, Sexualities, 2(3): 29I-308.

Arkutu, A. (1995). Family planning in Sub-Saharan Africa: Present status and future strategies. International Journal of Gynecology \& Obstetrics, 50:S27-S34.

Awusabo-Asare K., Abane A. M. and Kumi-Kyereme K. (2004). Adolescent Sexual and Reproductive Health in Ghana: A Synthesis ofResearch Evidence, Occasional Report, New York: The Alan Guttmacher Institute, 2004, No. 13.

Bongaarts, John (2008). Fertility Transitions in Developing Countries: Progress or Stagnation?Studies in Family Planning, 39(2): I05IIO.

Bongaarts, J., \& Casterline, J. (20|3). Fertility Transition: Is sub-Saharan Africa Different? Population and Development Review, 38(sI), I53168.

Busia, K. A. (1950). Report of a Social Survey of Sekondi-Takoradi. Accra: Government Printer.

Caldwell, J. C. (1965). Extended family obligations and education: A study of an aspect of demographic transition among Ghanaian university students. Population Studies, XIX(2): I 83-I 99.

Caldwell, J. C. and P. Caldwell (1987). The Cultural Context of High Fertility in sub-Saharan Africa.
Population and Development Review, I3(3): 409437.

Caldwell, J. C., I. O. Orubuloye and Pat Caldwell (1992). Fertility Decline in Africa: A New Type of Transition? Population and Development Review, I8(2): 2 | |-242.

Chiappero-Martinetti, E., Spreafico, A. M. C. and Quartapelle, L. (20I2). The Operationalization of the Capability Approach: A Toolkit. The Human Development, Capability and Poverty International Research Centre (HDCP-IRC) of the Institute for Advanced Study of Pavia (IUSS).

Dodoo, F. N. A., and A. E. Frost (2008). Gender in African Population Research: The Fertility/Reproductive Health Example. Annual Review of Sociology, 34: 43I-452.

Dodoo, F. N. A. and M. Tempenis (2002). Gender, Power, and Reproduction: Rural-Urban Differences in the Relationship Between Fertility Goals and Contraceptive Use in Kenya. Rural Sociology, 67: 46-70.

Eliason, S., Baiden, F., Quansah-Asare, G., GrahamHayfron, Y., Bonsu, D., Phillips, J. \& AwusaboAsare, K. (20I3). Factors influencing the intention of women in rural Ghana to adopt postpartum family planning. Reproductive health, I0(I): I-8.

Frank O. and J. Bongaarts (I99I). Behavioural and Biological Determinants of Fertility Transition in sub-Saharan Africa. Statistics in Medicine, I0(2): I6I-175.

Frost, A. E., and F. N. A. Dodoo (20I0). Adolescent Boys' Gendered Expectations for Bridewealth and Marriage Among the Akwapim of Southern Ghana. Marriage \& Family Review, Vol. 46, Issue I-2.

Frost, A. E., and F. N.A Dodoo (2009).Men are Missing from African Family Planning. Contexts, 8(I): 44-49.

Gedzi, Victor (2009). Women and Property Inheritance after Intestate Succession, Law I I I in Ghana. Paper presented at IAFFE Conference, Boston - 25-28 June 2009.

Ghana Statistical Service (20lI). Ghana Multiple Indicator Cluster Survey with an Enhanced Malaria Module and Biomarker, 20I I, Final Report. Accra, Ghana.

Ghana Statistical Service (2009). Ghana demographic and health survey, 2008. Accra, Ghana: Calverton, Md.: Ghana Statistical Service; ICF Macro.

Ghana Statistical Service (GSS), Ministry of Health, USAID, and UNICEF (2006).Ghana Multiple Indicator Cluster Survey 2006, GSS, MOH, USAID, UNICEF: Accra, Ghana and New York, NY.

Goody, J. (1969). Inheritance, Property, and Marriage in Africa and Eurasia. Sociology. 3: 55-76. 
Gould, W. T., \& Brown, M. S. (1996). A Fertility Transition in Sub-Saharan Africa? International Journal of Population Geography, 2(I): I-22.

Government of Ghana (1994).National Population Policy (Revised Edition, 1994). Accra: National Population Council.

Hagan, J. E., and Buxton C. (20|2). Contraceptive Knowledge, Perceptions and Use among Adolescents in Selected Senior High Schools in the Central Region of Ghana. Journal of Sociological Research, 3(2): |70-|80.

Heaton, T. B., and A. Darkwah (20II) Religious Differences in Modernization of the Family: Family Demographic Trends in Ghana. Journal of Family Issues32(I2): I576-I 596.

Kaufman, C. E., \& Stavrou, S. E. (2004). 'Bus fare please': The economics of sex and gifts among young people in urban South Africa. Culture, Health \& Sexuality, 6(5), 377-39I.

Kilson, M. D. (1967). Continuity and change in the $\mathrm{Ga}$ residential system. Journal of Sociology, 3: 8I-97.

Kpieta, B. A. and S. Z. Bonye (20|2). Land as A "God": The Gender Dimensions of its Wealth Creation among the Dagaabas in North-Western Ghana.European Scientific Journal, 8(|4): |09-|3|.

Kritz, M. M., \& Gurak, D. T. (1989). Women's status, education and family formation in sub-Saharan Africa. International Family Planning Perspectives, I00-I05.

Kumar, A., K. Kumar and D. Kumari (20/2). Consequences of Teenage Childbearing on Maternal and ChildHealth in India.Population Review, 5I(I): 69-84.

Kwankye, S. O., \& Cofie, E. (2015). Ghana's Population Policy Implementation: Past, Present and Future. African Population Studies, 29(2): I734-| 748.

Langille, D. B. (2007). Teenage pregnancy: trends, contributing factors and the physician's role. Canadian Medical Association Journal, 76(II), I60|-|602.

Lüscher, K. (20II). Ambivalence: A "Sensitizing Construct" for the Study and Practice of Intergenerational Relationships. Journal of Intergenerational Relationships, 9:19|-206.

Lüscher, K. (2004). Conceptualizing and uncovering intergenerational ambivalence. In K. Pillemer\& K. Lüscher (Eds.), Intergenerational ambivalences. New perspectives on parent-child relations in later life (pp. 23-62). Amsterdam, Netherlands: Elsevier.

Lüscher, K., \& Pillemer, K. (I 998). Intergenerational ambivalence: A new approach to the study of parent-child-relations in later life. Journal of Marriage and theFamily, 60(2), 4I3-425.
Manaf, M. R. A., Tahir, M. M., Sidi, H., Midin, M., Jaafar, N. R. N., Das, S., \&Malek, A.M. A. (20|4). Pre-marital sex and its predicting factors among Malaysian youths. Comprehensive psychiatry, 55, S82-S88.

Mbacke, C. (1994). Family Planning Programs and Fertility Transition in sub-Saharan Africa Population Dynamics of Sub-Saharan Africa by National Research Council.Population and Development Review, 20(I): 188-193.

McNamara, R. (1992). Family planning programs in Sub-Saharan Africa: case studies from Ghana, Rwanda, and the Sudan (Vol. I004). World Bank Publications.

Ministry of Youths and Sports (2010). National Youth Policy of Ghana: Towards an empowered youth, impacting positively on national development. Accra: Ministry of Youths and Sports.

Nukunya, G. K. (2003). Tradition and Change in Ghana: An introduction to Sociology. $2^{\text {nd }}$ Edition, Accra: Ghana Universities Press.

Oppong, C. (1974). Marriage among a matrilineal elite: a family study of Ghanaian

senior civil servants. Cambridge: Cambridge University Press.

Oppong, Christine (2005). Historical Perspectives on the Family and Fertility Change in Ghana. In S. Agyei-Mensah, J. B. Casterline and D. K. Agyemang (eds.) Reproductive Change in Ghana: Recent Patterns and Future Prospects. Accra: Department of Geography and Resource Development.

Pillemer, K. \& K. Lüscher (Eds.) (2004). Intergenerational Ambivalences. New Perspectives on Parent-child Relations in Later Life. Amsterdam, Netherlands: Elsevier.

Republic of Ghana (1985). Intestate Succession Law, I 985 III. Accra: Republic of Ghana.

Robeyns, I. (2005). The capability approach: a theoretical survey, Journal of Human Development, 6 (I): 93-II7.

Sauvain-Dugerdil, C. (2005) : La place de l'enfant dans les projets de vie: temporalité et ambivalence. In Legoff et al, Maternité et parcours de vie. L'enfant a-t-il toujours une place dans les projets des femmes en Suisse? Peter Lang, Berne, $28|-3| 6$.

Sauvain-Dugerdil, C. Antwi Bosiakoh, T. Diarra, S. Piraud, A. Diop, S. Anarfi, J. and S. Agyei-Mensah (20|4). 'Shaping the family': Individual's capabilities to exercise reproductive rights seen through a qualitative survey. African Population Studies, 28(2), 872-889.

Sen, A. (1999). Development as Freedom. Oxford: Oxford University Press. 
Shapiro, David and T. Gebreselassie (2008). Fertility Transition in Sub-Saharan Africa: Falling and Stalling. African Population Studies Vol. 22, No.2/Etude de la Population Africaine, 23(I): 323.

Shapiro, D., \& Tambashe, O. (1999). Fertility transition in urban and rural areas of sub-Saharan Africa. Population Research Institute, Pennsylvania State University.

Wong, M. L., Chan, R. K. W., Koh, D., Tan, H. H., Lim, F. S., Emmanuel, S., \& Bishop, G. (2009). Premarital sexual intercourse among adolescents in an Asian country: multilevel ecological factors. Pediatrics, I24(I), e44-e52.

UNDP (20/8). Human Development Reports Expected years of schooling. UNDP.

United Nations (20 I 3). World Population Prospects: The 2012 Revision. Highlights and Advance Tables. ESA/P/WP.228, Department of Economic and Social Affairs Population Division, New York.

Van Zantvliet, P. I., Kalmijn, M., \&Verbakel, E. (20I4). Parental involvement in partner choice: The case of Turks and Moroccans in the Netherlands. European Sociological Review, 30(3): 387-398. 